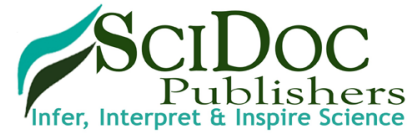

\section{Frequency and Determining Factors of Empiric Chemotherapy Dose Reduction in Patients with Non-Small Cell Lung Cancer}

Research Article

Kartolo $\mathrm{A}^{1,2}$, Wong $\mathrm{C}^{1 *}$, Cheng $\mathrm{S}^{1,3}$

${ }^{1}$ University of Toronto, Canada.

${ }^{2}$ Queen's University, Canada.

${ }^{3}$ Odette Cancer Centre, Sunnybrook Health Sciences Complex, Canada.

\title{
Abstract
}

Objectives: To determine the frequency and key factors regarding empiric chemotherapy dose reductions (ECDR) in nonsmall cell lung cancer (NSCLC) patients.

Methods: This retrospective study involved the chart review of all histologically confirmed NSCLC patients receiving chemotherapy at the Odette Cancer Centre, Sunnybrook Health Sciences Complex, from 2013-2014. The frequency of ECDR and potential impacting factors were recorded and analyzed on SPSS v16.0. Results were expressed in percentages, P-values, and Cramer's V.

Results: Our findings $(\mathrm{N}=134)$ suggested patients with moderate kidney disease stages were statistically associated with ECDR $(29 \%$ vs. $24 \%$ vs. $50 \%$ for stage I, II, and III respectively, $\mathrm{p}=0.031, \varphi=0.235$, df $=2)$. Patients aged 61 and above (39\% vs. $\left.14 \%, \mathrm{P}=0.001, \varphi_{c}=0.23, \mathrm{df}=1\right)$, polypharmacy of 4 or more medications $\left(24 \%\right.$ vs. $44 \%, \mathrm{p}=0.017, \varphi_{c}=0.21$, $\mathrm{df}=1)$, presence of kidney disease $(43 \%$ vs. $24 \%, \mathrm{P}=0.024, \varphi=0.20, \mathrm{df}=1)$, and palliative intent $(40 \%$ vs. $12 \%, \mathrm{p}=$ $0.0027, \varphi=0.26, \mathrm{df}=1)$ showed statistically significant, but weak association with ECDR. Combinations ( 3 or more) of the impacting factors as mentioned above showed statistically significant association with ECDR $\left(75 \% \mathrm{vs} 42 \%, \mathrm{P}=0.00, \varphi_{c}\right.$ $=0.308)$. The degree of ECDR were positively correlated to patient age, moderate stage chronic kidney disease, and having combinations of impacting factors.

Conclusions and Relevance: ECDR was common in the NSCLC patients (33\%), particularly in the elderly, polypharmacy, palliative care and kidney disease population. Variances might exist among physicians, which might lead to clinically significant outcomes. Guidance and future studies for ECDR is crucial especially as Ontario's senior population grows.

Keywords: Empiric Chemotherapy Dose Reduction; Non-Small Cell Lung Cancer; Impacting Factors.

\section{Introduction}

Non-small cell lung cancer (NSCLC) is a disease of the elderly with a median age diagnosis at seventy-one years of age [1]. Unfortunately, the risk of chemotherapy toxicities, such as mucositis, myelosuppression, neuropathy, and cardiomyopathy, increases with advancing age [2-4]. It has been estimated that frailty in elderly cancer patients can be as high as $42 \%$ [2]. This has led to the practice of empiric chemotherapy dose reductions (ECDR) in elderly patients to prevent morbidity and mortality [2, $5,6]$. A multisite cohort study involving elderly cancer patients demonstrates that $29 \%$ of those with advanced cancer have experienced a dose reduction in their first chemotherapy cycle [3].

There are existing guidelines on chemotherapy dosage for patients with NSCLC [7-9]. However, no guidelines are available in assisting physicians on how to manage patients with NSCLC who may also require ECDR. For that reason, clinical judgment and experience play a significant role in treatment decisions. However, this may result in potential biases and variation among physicians. Therefore, it is imperative to seek and understand the possible variables to avoid unnecessary chemotherapy toxicities in the frail elderly or under treatment of fit elderly patients. To

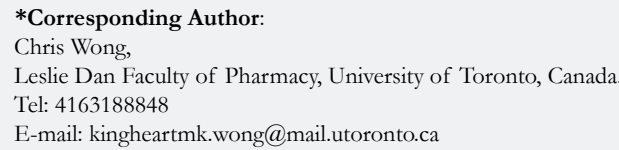

Citation: Kartolo A, Wong C, Cheng S (2017) Frequency and Determining Factors of Empiric Chemotherapy Dose Reduction in Patients with Non-Small Cell Lung Cancer. Int J Cancer Stud Res. 6(1), 115-121. doi: http://dx.doi.org/10.19070/2167-9118-1700022

Copyright: Wong $\mathbf{C}^{\circ}$ 2017. This is an open-access article distributed under the terms of the Creative Commons Attribution License, which permits unrestricted use, distribution and reproduction in any medium, provided the original author and source are credited. 
date, there are few existing studies that explore potential factors in ECDR in specific population such as elderly and obesity but not in NSCLC population $[2,10]$. This study aims to determine the frequency and key factors regarding empiric chemotherapy dose adjustments in patients with NSCLC.

\section{Methodology}

\section{Setting, Patients, Study Design, and Measurement Outcomes}

We obtained ethics approval from Sunnybrook Research Ethics Board on October 2014. We conducted a retrospective study utilizing hospital chart review and Cancer Care Ontario's Oncology Patient Information System (OPIS). We included patients from 2013-2014 with histologically confirmed NSCLC of all stages, who were receiving chemotherapy for all treatment intent in Odette Cancer Centre, Sunnybrook Health Sciences Complex. We defined ECDR as any decreases in the prescribed chemotherapy dosage as compared to the initial pre-calculated chemotherapy dosage by OPIS. We excluded patients with other types of lung cancers, not receiving chemotherapy, receiving oral chemotherapy, or participating in clinical trials. There was no exclusion criteria based on ages, genders, ethnicities, or otherwise. We identified the eligible patients via computerized order entry database at Odette Cancer Centre which captured all NSCLC patients during this time period.

We collected demographic and medical information including gender, age, Body Mass Index (BMI), distance to health care, comorbidities, number of medications, cancer stage, current chemotherapy regimen (platinum vs. non-platinum), empiric dosage reduction, lines of therapy, treatment of intent, kidney stage, and Edmonton Symptom Assessment System (ESAS).

\section{Statistical Analysis}

There were 304 patients in the initial search through our database entry. 170 patients were omitted based on exclusion criteria as mentioned above. We conducted descriptive statistical analyses on SPSS v16.0 to evaluate any potential impacting factors in determining the presence of ECDR. We also conducted secondary analysis in determining combinations of potential impacting factors in the role of ECDR decision-making process. Fisher's exact test or Chi-Square test was used where appropriate. The study end-points were expressed in percentages, and we set P-value less than 0.05 to indicate statistically significant results. If any potential impacting factors were statistically significant, we determined the strength of the association by setting Cramer's $\mathrm{V}$ $\varphi_{c}=0.3$ (degree of freedom $\left.=1\right), 0.21$ (degree of freedom $=2$ ), and 0.17 (degree of freedom $=3$ ) to indicate medium correlation effect $[11,12]$.

\section{Results}

\section{Demographic and Health Information Result (Table 1)}

Our study population $(\mathrm{N}=134)$ indicated similar demographic distribution in terms of gender ( $47 \%$ male vs. $53 \%$ female). Most patients resided in the GTA $(76 \%)$. The patients were aged 61 and above $(74 \%)$, within the normal BMI $(58 \%)$, and presented with stage 4 NSCLC $(78 \%)$ at the time.

Nearly half $(47 \%)$ of the patients had kidney disease of varying stages $(34 \%, 38 \%, 28 \%$ for stage I, II, and III, respectively); $13 \%$ of the patients had cardiac disease. Less than one-tenth (7\%) of the patients were found to have both kidney and cardiac diseases. The majority of the sample $(74 \%)$ did not have a medical history of cancer. Approximately $46 \%$ of patients took more than 4 medications per day, with $15 \%$ and $11 \%$ of them taking anticoagulants and metformin/glyburide respectively.

Platinum-based chemotherapy was used on $64 \%$ of the patients, and $33 \%$ of patients received ECDR of varying levels. The intent of treatment was mostly palliative $(75 \%)$. Prior to receiving their first chemotherapy, most patients indicated mild symptoms and scored $0-3$ across ESAS in terms of feeling unwell (58\%), anxiety $(79 \%)$, depression $(77 \%)$, shortness of breath $(76 \%)$, lack of appetite $(79 \%)$, nausea $(96 \%)$, drowsiness $(75 \%)$, fatigue $(56 \%)$, and pain $(82 \%)$.

\section{Study Result (Table 2, 3, and 4)}

Our findings suggested ECDR are frequent in the NSCLC population (33\%). Only moderate kidney stages showed statistically significant association with ECDR $(29 \%$ vs. $24 \%$ vs. $50 \%$ for stage I, II, and III respectively, $\mathrm{p}=0.031, \varphi_{c}=0.235 \mathrm{df}$ =2). There were 38 patients with moderate kidney disease (CKD Stage 3). 19 of the 38 patients received ECDR, with one-third of them receiving $20 \%$ or more chemotherapy dose reduction of platinum type $(58 \%)$ in a palliative setting $(82 \%)$. Most were female $(61 \%)$ and above the age of $61(90 \%)$. Majority (87\%) had stage 4 NSCLC. Approximately $25 \%$ of the moderate chronic kidney disease patients had 3 major symptom burdens based on ESAS scores of 4 or above in a category. Interestingly, none showed statistically significant association with ECDR in this sub-population of moderate stage chronic kidney disease in the setting of NSCLC.

In addition, we identified patients aged 61 and above $(39 \%$ vs. $\left.14 \%, \mathrm{P}=0.001, \varphi_{c}=0.23, \mathrm{df}=1\right)$, polypharmacy of 4 or more medications $\left(24 \%\right.$ vs. $\left.44 \%, \mathrm{p}=0.017, \varphi_{c}=0.21, \mathrm{df}=1\right)$, presence of kidney disease ( $43 \%$ vs. $\left.24 \%, P=0.024, \varphi_{c}=0.20, \mathrm{df}=1\right)$, and palliative intent ( $40 \%$ vs. $\left.12 \%, \mathrm{p}=0.0027, \varphi_{c}=0.26, \mathrm{df}=1\right)$ to have statistically significant but weak association with ECDR. However, any 3 or more combinations of the 5 impacting factors mentioned above showed statistically significant association with $\operatorname{ECDR}\left(75 \%\right.$ vs $\left.42 \%, \mathrm{P}=0.00, \varphi_{c}=0.308\right)$.

Our study also indicated a higher empirical chemotherapy dose reduction of $20 \%$ or more in patient population of age 61 or above $\left(\mathrm{P}=0.002, \varphi_{c}=0.30, \mathrm{df}=3\right)$, moderate stage chronic kidney disease $(\mathrm{P}=0.018, \varphi=0.27, \mathrm{df}=3)$, and having a combination of 2 or more of the 5 impacting factors $\left(\mathrm{P}=0.002, \varphi_{c}=0.30\right.$, df $=3)$. There were no differences in the extent of ECDR in the subgroup population of polypharmacy or palliative intent.

No statistically significant associations were found in patients with $\mathrm{BMI} \geq 25$, cardiac or cardiac-combination history, previous cancer history, presence of anticoagulants or metformin/ glyburide, chemotherapy types, or any ESAS components and its combinations. 
Table 1. Demographic Information and Health Information.

\begin{tabular}{|c|c|}
\hline & Percentage (Frequency); N = 134, unless specified otherwise \\
\hline $\begin{array}{l}\text { Gender } \\
\text { Male } \\
\text { Female }\end{array}$ & $\begin{array}{l}47 \%(63) \\
53 \%(71)\end{array}$ \\
\hline $\begin{array}{c}\text { Age } \\
<50 \\
51-60 \\
61-70 \\
>71\end{array}$ & $\begin{array}{c}6 \%(8) \\
20 \%(27) \\
35 \%(47) \\
39 \%(52)\end{array}$ \\
\hline $\begin{array}{c}\text { BMI } \\
18.5-24.9 \\
25.0-29.9 \\
30 \text { and above }\end{array}$ & $\begin{array}{l}57.5 \%(77) \\
34.3 \%(46) \\
8.2 \%(11)\end{array}$ \\
\hline $\begin{array}{c}\text { Distance of Health Care } \\
\text { GTA } \\
\text { Non-GTA }\end{array}$ & $\begin{array}{c}76 \%(102) \\
24 \%(32)\end{array}$ \\
\hline $\begin{array}{c}\text { Cancer Stage } \\
1 \\
2 \\
3 \\
4\end{array}$ & $\begin{array}{c}0 \%(0) \\
8 \%(11) \\
14 \%(18) \\
78 \%(105)\end{array}$ \\
\hline $\begin{array}{c}\text { Current Chemotherapy } \\
\text { Platinum } \\
\text { Non-Platinum }\end{array}$ & $\begin{array}{l}64 \%(86) \\
36 \%(48)\end{array}$ \\
\hline $\begin{array}{c}\text { Dosage Reduction } \\
10 \% \text { and below } \\
11-20 \% \\
21 \text { and above } \\
\text { No Dose Reduction }\end{array}$ & $\begin{array}{c}4 \%(5) \\
15 \%(20) \\
14 \%(19) \\
67 \%(90)\end{array}$ \\
\hline $\begin{array}{c}\text { Lines of Therapy } \\
\text { First } \\
\text { Second } \\
\text { Third }\end{array}$ & $\begin{array}{l}73 \%(98) \\
19 \%(25) \\
8 \%(11)\end{array}$ \\
\hline $\begin{array}{c}\text { Treatment of Intent } \\
\text { Neoadjuvant } \\
\text { Adjuvant } \\
\text { Curative } \\
\text { Palliative } \\
\end{array}$ & $\begin{array}{c}2 \%(3) \\
10 \%(14) \\
13 \%(17) \\
75 \%(100)\end{array}$ \\
\hline $\begin{array}{c}\text { ESAS Score }(\mathbf{N}=103) \\
\text { Feeling Unwell } \\
0-3 \\
4-10 \\
\text { Anxiety } \\
0-3 \\
4-10 \\
\text { Depression } \\
0-3 \\
4-10 \\
\text { Shortness of Breath } \\
0-3 \\
4-10 \\
\text { Lack of Appetite } \\
0-3 \\
4-10 \\
\text { Nausea } \\
0-3 \\
4-10 \\
\text { Drowsiness } \\
0-3 \\
4-10 \\
\text { Fatigue } \\
0-3 \\
4-10 \\
\text { Pain } \\
0-3 \\
4-10\end{array}$ & $\begin{array}{c}58 \%(60) \\
42 \%(43) \\
79 \%(81) \\
21 \%(22) \\
77 \%(79) \\
23 \%(24) \\
76 \%(78) \\
24 \%(25) \\
79 \%(81) \\
21 \%(22) \\
96 \%(99) \\
4 \%(4) \\
75 \%(77) \\
25 \%(26) \\
56 \%(57) \\
44 \%(46)\end{array}$ \\
\hline
\end{tabular}


Table 2. Reasons for Reduction and its Power Analysis.

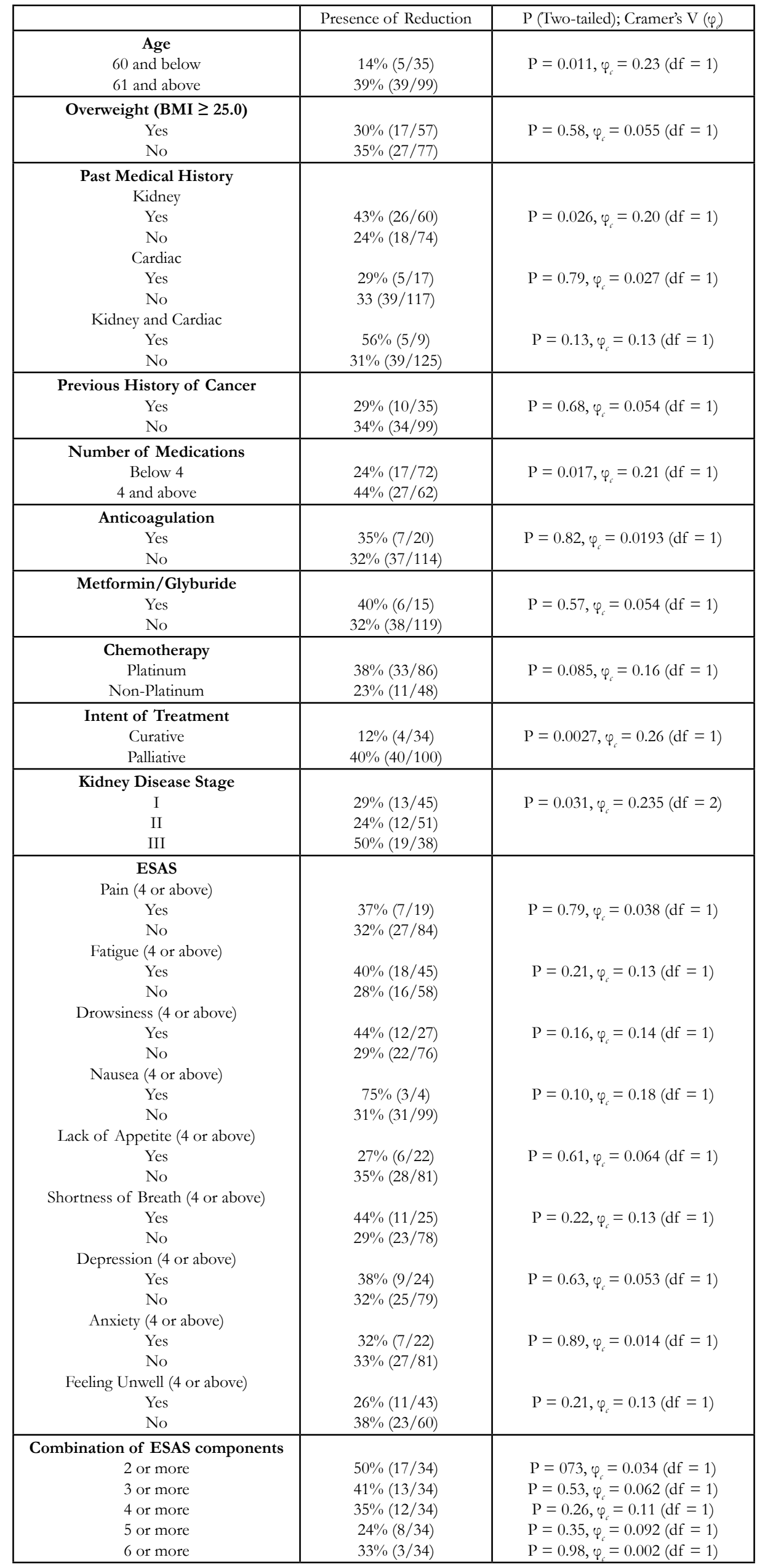


Table 3. Subgroup Analysis for Reasons for Reduction and its Power Analysis.

\begin{tabular}{|c|c|c|}
\hline & Presence of Reduction & P (Two-tailed); Cramer's V $(\varphi c)$ \\
\hline $\begin{array}{l}\text { Combinations } \\
2 \text { or above } \\
3 \text { or above }\end{array}$ & $\begin{array}{l}91 \%(40 / 44) \\
75 \%(33 / 44)\end{array}$ & $\begin{array}{c}\mathrm{P}=0.002, \varphi_{c}=0.262(\mathrm{df}=1) \\
\mathrm{P}=0.00, \varphi_{c}=0.308(\mathrm{df}=1)\end{array}$ \\
\hline \multicolumn{3}{|c|}{ Moderate Kidney Disease $(\mathbf{N}=38)$} \\
\hline & Presence of Reduction & P (Two-tailed); Cramer's V $(\varphi c)$ \\
\hline $\begin{array}{l}\text { Age } \\
60 \text { and below } \\
61 \text { and above }\end{array}$ & $\begin{array}{c}24 \%(1 / 4) \\
53 \%(18 / 34)\end{array}$ & $\mathrm{P}=0.60, \varphi_{c}=0.17(\mathrm{df}=1)$ \\
\hline $\begin{array}{c}\text { Overweight (BMI } \geq 25.0) \\
\text { Yes } \\
\text { No } \\
\end{array}$ & $\begin{array}{c}44 \%(4 / 9) \\
52 \%(15 / 29)\end{array}$ & $P=0.50, \varphi_{c}=0.70(\mathrm{df}=1)$ \\
\hline $\begin{array}{c}\text { Past Medical History } \\
\text { Kidney } \\
\text { Yes } \\
\text { No } \\
\text { Cardiac } \\
\text { Yes } \\
\text { No } \\
\text { Kidney and Cardiac } \\
\text { Yes } \\
\text { No } \\
\end{array}$ & $\begin{array}{c}57 \%(13 / 23) \\
40 \%(6 / 15) \\
\\
67 \%(2 / 3) \\
49 \%(17 / 35) \\
\\
67 \%(2 / 3) \\
49 \%(17 / 35) \\
\end{array}$ & $\begin{array}{l}P=0.32, \varphi_{c}=0.32(\mathrm{df}=1) \\
P=0.50, \varphi_{c}=0.55(\mathrm{df}=1) \\
P=0.50, \varphi_{c}=0.55(\mathrm{df}=1)\end{array}$ \\
\hline $\begin{array}{c}\text { Previous History of Cancer } \\
\text { Yes } \\
\text { No } \\
\end{array}$ & $\begin{array}{l}58 \%(7 / 12) \\
46 \%(12 / 26)\end{array}$ & $\mathrm{P}=0.49, \varphi_{c}=0.49(\mathrm{df}=1)$ \\
\hline $\begin{array}{c}\text { Number of Medications } \\
\text { Below } 4 \\
4 \text { and above } \\
\end{array}$ & $\begin{array}{l}50 \%(8 / 16) \\
50 \%(11 / 22)\end{array}$ & $\mathrm{P}=1.0, \varphi_{c}=0(\mathrm{df}=1)$ \\
\hline $\begin{array}{c}\text { Anticoagulation } \\
\text { Yes } \\
\text { No } \\
\end{array}$ & $\begin{array}{c}50 \%(2 / 4) \\
50 \%(17 / 34)\end{array}$ & $\mathrm{P}=1.0, \varphi_{c}=0(\mathrm{df}=1)$ \\
\hline $\begin{array}{c}\text { Metformin/Glyburide } \\
\text { Yes } \\
\text { No } \\
\end{array}$ & $\begin{array}{c}40 \%(2 / 5) \\
52 \%(17 / 33)\end{array}$ & $\mathrm{P}=0.50, \varphi_{c}=0.63(\mathrm{df}=1)$ \\
\hline $\begin{array}{c}\text { Chemotherapy } \\
\text { Platinum } \\
\text { Non-Platinum }\end{array}$ & $\begin{array}{c}59 \%(13 / 22) \\
38 \%(6 / 16)\end{array}$ & $\mathrm{P}=0.19, \varphi_{c}=0.19(\mathrm{df}=1)$ \\
\hline $\begin{array}{c}\text { Intent of Treatment } \\
\text { Curative } \\
\text { Palliative } \\
\end{array}$ & $\begin{array}{c}52 \%(16 / 31) \\
43 \%(3 / 7) \\
\end{array}$ & $\mathrm{P}=1, \varphi_{c}=0.069(\mathrm{df}=1)$ \\
\hline 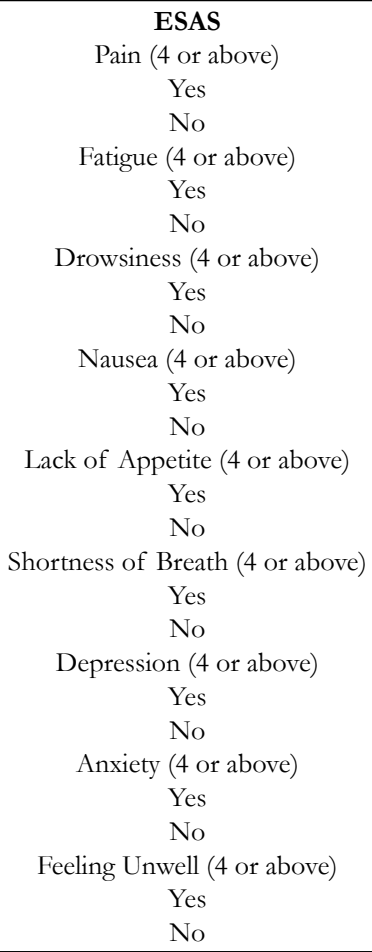 & $\begin{array}{c}25 \%(1 / 4) \\
60 \%(15 / 25) \\
46 \%(6 / 13) \\
63 \%(10 / 16) \\
63 \%(5 / 8) \\
52 \%(11 / 21) \\
0 \%(0 / 0) \\
55 \%(16 / 29) \\
25 \%(1 / 4) \\
60 \%(15 / 25) \\
43 \%(3 / 7) \\
59 \%(13 / 22) \\
25 \%(1 / 4) \\
60 \%(15 / 25) \\
25 \%(1 / 4) \\
60 \%(15 / 25) \\
43 \%(3 / 7) \\
59 \%(13 / 22)\end{array}$ & $\begin{array}{l}\mathrm{P}=0.30, \varphi_{c}=0.24(\mathrm{df}=1) \\
\mathrm{P}=0.47, \varphi_{c}=0.16(\mathrm{df}=1) \\
\mathrm{P}=0.70, \varphi_{c}=0.091(\mathrm{df}=1) \\
\mathrm{P}=1, \varphi_{c}=0(\mathrm{df}=1) \\
\mathrm{P}=0.30, \varphi_{c}=0.24(\mathrm{df}=1) \\
\mathrm{P}=0.67, \varphi_{c}=0.14(\mathrm{df}=1) \\
\mathrm{P}=0.30, \varphi_{c}=0.24(\mathrm{df}=1)\end{array}$ \\
\hline
\end{tabular}




\begin{tabular}{|c|c|c|}
\hline Combination of ESAS components & & \\
\hline 2 or more & $31 \%(5 / 16)$ & $\mathrm{P}=0.10, \varphi_{c}=0.30(\mathrm{df}=1)$ \\
\hline 3 or more & $25 \%(4 / 16)$ & $\mathrm{P}=0.44, \varphi_{c}=0.15(\mathrm{df}=1)$ \\
\hline 4 or more & $19 \%(3 / 16)$ & $\mathrm{P}=0.81, \varphi_{c}=0.044(\mathrm{df}=1)$ \\
\hline 5 or more & $13 \%(2 / 16)$ & $\mathrm{P}=0.82, \varphi_{c}=0.042(\mathrm{df}=1)$ \\
\hline 6 or more & $0 \%(0 / 16)$ & $\mathrm{P}=0.10, \varphi_{c}=0.30(\mathrm{df}=1)$ \\
\hline
\end{tabular}

Combinations of Moderate Kidney Disease, Comorbidities (Kidney Disease), Age Above 61, Polypharmacy (Medications 4 and above), Palliative Intent In Relation to EDCR

Table 4. Extent of Empiric Chemotherapy Dose Reduction In Relation to Impacting Factors.

\begin{tabular}{|c|c|c|c|c|c|}
\hline & \multicolumn{4}{|c|}{ Extent of Empiric Chemotherapy Dose Reduction } & \multirow{2}{*}{$\begin{array}{c}\text { P Value, } \\
\text { Cramer's V }(\varphi \mathrm{c})\end{array}$} \\
\hline & None & $10 \%$ and Below & $11 \%$ to $20 \%$ & $21 \%$ and Above & \\
\hline Age 61 or Above & $67 \%(60 / 90)$ & $40 \%(2 / 5)$ & $91 \%(19 / 21)$ & $100 \%(18 / 18)$ & $\mathrm{P}=0.002, \varphi_{c}=0.30(\mathrm{df}=3)$ \\
\hline Polypharmacy (4 or above) & $61 \%(55 / 90)$ & $40 \%(2 / 5)$ & $38 \%(8 / 21)$ & $39 \%(7 / 18)$ & $\mathrm{P}=0.11, \varphi_{c}=0.21(\mathrm{df}=3)$ \\
\hline $\begin{array}{c}\text { Moderate Stage Chronic Kidney } \\
\text { Disease }\end{array}$ & $21 \%(19 / 90)$ & $20 \%(1 / 5)$ & $38 \%(8 / 21)$ & $56 \%(10 / 18)$ & $\mathrm{P}=0.018, \varphi_{c}=0.27(\mathrm{df}=3)$ \\
\hline Comorbidities (Kidney Disease) & $38 \%(34 / 90)$ & $20 \%(1 / 5)$ & $52 \%(11 / 21)$ & $78 \%(14 / 18)$ & $\mathrm{P}=0.010, \varphi_{c}=0.29(\mathrm{df}=3)$ \\
\hline Palliative Intent & $67 \%(60 / 90)$ & $100 \%(5 / 5)$ & $91 \%(19 / 21)$ & $89 \%(17 / 18)$ & $\mathrm{P}=0.24, \varphi_{c}=0.27(\mathrm{df}=3)$ \\
\hline $\begin{array}{l}\text { Combinations of } 2 \text { or More Im- } \\
\text { pacting Factors as Shown Above }\end{array}$ & $67 \%(60 / 90)$ & $60 \%(3 / 5)$ & $95 \%(20 / 21)$ & $94 \%(17 / 18)$ & $\mathrm{P}=0.002, \varphi_{c}=0.30(\mathrm{df}=3)$ \\
\hline
\end{tabular}

\section{Discussion}

\section{Result Interpretation}

Our studies indicated that medical oncologists in Sunnybrook Health Sciences Complex considered moderate stage of chronic kidney disease to determine whether or not they performed ECDR. In addition, our study suggested that medical oncologists considered multiple combined impacting factors -3 or more of aged 61 or above, polypharmacy, presence of kidney disease (particularly in moderate stage), and palliative intent - rather than a single factor to determine the practice of ECDR. The extent to which ECDR was performed (i.e. dose reduction of $10 \%$ or less, $11 \%-20 \%$, or $21 \%$ or above) were correlated with patient age, moderate stage chronic kidney disease, and having combinations of impacting factors.

Age and presence of kidney disease of moderate severity were identified as factors in determining the presence of ECDR. Many studies were done to evaluate the role of aging in affecting the pharmacokinetic and pharmacodynamics of chemotherapy [1315]. Available data showed inconsistent results in age-related chemotherapy pharmacokinetic changes but clear association with age-related chemotherapy pharmacodynamics changes [13]. In other words, elderly patients tend to experience more adverse reaction by chemotherapy when compared to younger patients. The increased toxicity risk in the elderly cancer patient might be due to the decrease in volume of distribution, hepatic metabolism, and renal excretion $[5,13,16,17]$. Kidney disease as a factor for ECDR was important because many chemotherapy agents such as cisplatin and carboplatin are cleared via the kidneys [5]. However, it would be important to note that serum creatinine might not reflect true renal function in the elderly [17]. Despite glomerular filtration rate reduced at a rate of $0.75 \mathrm{~mL} / \mathrm{min}$ after the age of 40 , approximately $30 \%$ of patients did not have increased serum creatinine level due to simultaneous muscle mass loss $[16,17]$..
Thus, serum creatinine alone might not be an appropriate marker to evaluate presence of kidney disease as an ECDR determining factor.

The patient population taking 4 or more medications was also found to be an important factor for ECDR. This finding further strengthened the complex interactions between chemotherapy and other medications $[18,19]$. A two-centre cross-sectional study identified that $58 \%$ of cancer patients had at least one potential adverse drug interaction [20]. In relation to chemotherapy adverse reactions, potential drug interactions increased proportionally to the number of medications involved [20]. This was consistent to our finding that oncologists tend to perform ECDR in patients with polypharmacy.

In addition to the quantity of medications, types of medications were also important in evaluating potential adverse drug interaction with chemotherapy [21, 22]. Previous studies had identified anticoagulants and oral hypoglycemics such as metformin/ glyburide to be 'high risk' medication classes for adverse drug events in the elderly population based on the Beers, Zhang, and Drugs to Avoid in the Elderly criteria [21, 22]. However, their results suggested no association between polypharmacy and potentially inappropriate medication use with chemotherapyrelated toxicity or hospitalization in seniors with cancer [21]. This was also consistent with our findings that oncologists did not correlate anticoagulants and metformin/glyburide as part of their ECDR determining factors. Overall, our study suggested that oncologists took account the quantity, but not quality of medications as their ECDR determining factors.

The treatment goals in our patient population of advanced NSCLC should focus on symptom relief, quality of life improvement, and possible survival prolongation [9]. Current BCCA guidelines recommend to not extend platinum-based doublet chemotherapy beyond 4 to 6 cycles as first-line palliative chemotherapy, given 
that it might not provide survival benefit but increase cumulative toxicity profiles. Instead, the guideline recommends a single agent maintenance therapy when appropriate. This was consistent with our finding of palliative intent as one of the major factors in performing ECDR.

Lung cancer medical oncologists had higher rates of performing ECDR when using platinum-based chemotherapy; however, this finding did not reach statistical significance. Interestingly, none of the components of ESAS or its combinations were associated with ECDR. We suspected that major symptom burden was more related to contraindication of initiating chemotherapy rather than performing ECDR.

\section{Study Limitations}

There were two study limitations. First, we could not identify any validated score of performance status in the chart review. As such, we chose to incorporate ESAS score as means to approximate patients' performance status. This might underestimate our results. Nonetheless, various studies had shown good correlation between ESAS scores and various validated performance status scores (e.g., Simmonds Functional Assessment Tool, Karnofsky Performance Status, Functional Assessment of Cancer TherapyLung Patients, etc.) [23-25]. Therefore, we believed we had minimized our first study limitation. Second, our study only took into account the sample size at one cancer centre, which may underestimate the results. However, such underestimation might be minimized as we also incorporated potential impacting factors derived from literature reviews [2-10]. Thus, we believed our results would be generalizable.

Despite the limitations, our study provided some understanding in the factors determining the presence of ECDR. Future studies evaluating patient outcomes in multiple cancer centers secondary to empiric dose reductions are recommended. Such findings will be useful in developing guidelines in the future.

\section{Conclusion}

This study highlighted the importance of guidance in ECDR in the NSCLC population. This study showed that $33 \%$ of patients received ECDR. The vast majority of the dose reductions were performed in the elderly, polypharmacy, palliative intent, and kidney disease population. Except for moderate stage chronic kidney disease patients, medical oncologists tend to use combinations of impacting factors rather than a single entity to determine the practice of ECDR. The extent to which ECDR was performed (i.e. dose reduction of $10 \%$ or less, $11 \%-20 \%$, or $21 \%$ or above) also showed correlation with patient age, moderate stage chronic kidney disease, and having combinations of impacting factors. More studies are required in the future to examine the variances in ECDR amongst medical oncologists, which might lead to clinically significant outcomes. As our population ages rapidly, the incidence of ECDR would increase dramatically. Thus, it is important to increase awareness of such dosing patterns and to further evaluate the association between ECDR and its intended outcomes in future studies.

\section{References}

[1]. Subramanian J, Morgensztern D, Goodgame B, Gao F, Govindan R, et al., (2010) Distinctive characteristics of non-small cell lung cancer (NSCLC) in the young: a surveillance, epidemiology, and end results (SEER) analysis. J Thorac Oncol. 5(1): 23-28.

[2]. Swaminathan D, Swaminathan V (2015) Geriatric oncology: problems with under-treatment within this population. Cancer Biol Med. 12(4): 275-283.

[3]. Handforth C, Clegg A, Young C, Selby PJ, Young J, et al., (2015) The prevalence and outcomes of frailty in older cancer patients: a systematic review. Ann Oncol. 26(6): 1091- 1101.

[4]. Klepin H, Rodin M, Hurria A (2015) Treating Older Adults with Cancer: Geriatric Perspectives. Am Soc Clin Oncology Educ Book. e544-52.

[5]. Wildiers $\mathrm{H}$ (2007) Mastering chemotherapy dose reduction in elderly cancer patients. Eur J Cancer. 43(15): 2235-2241.

[6]. Froesch P, Martucci F, Gyorik S, Dutly AE, Cafarotti S (2014) Management of non-small cell lung cancer in the elderly. Eur J Int Med. 25(10): 884-894.

[7]. Kulkarni S, Vella ET, Cheng S, Ung TC, Ellis PM, et al., (2015) The Use of Systemic Treatment in the Maintenance of Patients with Nonsmall Cell Lung Cancer: A Systematic Review. J Thorac Oncol. 11(7): 7-22.

[8]. Bradbury P, Sivajohanathan D, Chan A, Ung Y, Ellis PM, et al., (2016) Postoperative Adjuvant Systemic Therapy in Completely Resected Non-Small Cell Lung Cancer: A Systematic review. Clin Lung Cancer. Pii: S1525-7304.

[9]. BC Cancer Agency. Lung cancer management guidelines, 2013.

[10]. Thompson LA, Lawson AP, Sutphin SD, Adams VR, Steinke D (2010) Description of Current Practices of Empiric Chemotherapy Dose Adjustment in Obese Adult Patients. J Oncol Pract. 6(3): 141-145.

[11]. Cohen Jacob (1988) Statistical power analysis for the behavioral sciences. Philadelphia: Lawrence Erlbaum Associates.

[12]. Mukaka MM (2012) Statistic corner: a guide to appropriate use of correlation coefficient in medical research. Malawi Med J. 24(3): 69-71.

[13]. Lichtman SM, Wildiers H, Launay-Vacher V, Steer C, Aapro M, et al., (2007) International Society of Geriatric Oncology (SIOG) recommendations for the adjustment of dosing in elderly cancer patients with renal insufficiency. Eur J Cancer. 43(1): 14-34.

[14]. Tam-McDevitt J (2008) Polypharmacy, aging, and cancer. Oncology. 22(9): 1052-5.

[15]. Hurria A, Lichtman SM (2007) Pharmacokinetics of chemotherapy in the older patient. Cancer Control. 14(1): 32-43.

[16]. Lindeman RD, Tobin J, Shock NW (1985) Longitudinal studies on the rate of decline in renal function with age. J Am Geriatr Soc. 33(4): 278-285.

[17]. Fehrman-Ekholm I, Skeppholm L (2004) Renal function in the elderly ( $>70$ years old) measured by means of iohexol clearance, serum creatinine, serum urea and estimated clearance. Scand J Urol Nephrol. 38(1): 73-77.

[18]. Maggiore RJ, Gross CP, Hurria A (2010) Polypharmacy in older adults with cancer. Oncologist Express. 15(5): 507-522.

[19]. Lees J, Chan A (2011) Polypharmacy in elderly patients with cancer: clinical implications and management. Lancet oncology. 12(13): 1249-57.

[20]. Swart EL, Boven E, Boom FA, Van Leeuwen RFW, Hugtenburg JG (2011) Potential drug interactions in cancer therapy: a prevalence study using an advanced screening method. Ann Oncology. 22(10): 2334-41.

[21]. The American Geratrics Society 2015 Beers Criteria Update Expert Panel (2015) American Geriatrics Society 2015 Updated Beers Criteria for Potentially Inappropriate Medication Use in Older Adults. J Am Geriatr Soc. 63(11): 2227-2246.

[22]. Maggiore RJ, Dale W, Gross CP, Feng T, Tew WP, et al., (2004) Polypharmacy and potentially inappropriate medication use in older adults with cancer undergoing chemotherapy: effect on chemotherapy-related toxicity and hospitalization during treatment. J Am Geriatr Soc. 61(8): 1404-12.

[23]. Change VT, Hwang SS, Feuerman M (2000) Validation of the Edmonton Symptom Assessment Scale. Cancer. 88(9): 2164-71.

[24]. Moro C, Brunelli C, Miccinesi G, Fallai M, Morino P, et al., (2006) Edmonton symptoms assessment scale: Italian validation in two palliative care settings. Support Care Cancer. 14(1): 30-7.

[25]. Montoya M, Fossella F, Palmer JL, Kaur G, Pace EA, et al., (2006) Objective evaluation of physical function in patients with advanced lung cancer: a preliminary report. J Palliat Med. 9(2): 309-16. 